\title{
Visibility and Citation Impact
}

\author{
Nader Ale Ebrahim ${ }^{1}$, Hadi Salehi ${ }^{2}$, Mohamed Amin Embi ${ }^{3}$, Farid Habibi Tanha ${ }^{4}$, Hossein Gholizadeh ${ }^{5}$ \& Seyed \\ Mohammad Motahar ${ }^{6}$ \\ ${ }^{1}$ Research Support Unit, Centre of Research Services, Institute of Research Management and Monitoring (IPPP), \\ University of Malaya, Malaysia \\ ${ }^{2}$ Faculty of Literature and Humanities, Najafabad Branch, Islamic Azad University, Najafabad, Isfahan, Iran \\ ${ }^{3}$ Faculty of Education, Universiti Kebangsaan Malaysia, Bangi, Malaysia \\ ${ }^{4}$ Department of Financial Sciences, University of Economic Sciences, Tehran, Iran \\ ${ }^{5}$ Department of Biomedical Engineering, Faculty of Engineering, University of Malaya, Kuala Lumpur, \\ Malaysia \\ ${ }^{6}$ Faculty of Information Science and Technology, Universiti Kebangsaan Malaysia, Bangi, Malaysia \\ Correspondence: Nader Ale Ebrahim, Research Support Unit, Centre of Research Services, Institute of Research \\ Management and Monitoring (IPPP), University of Malaya, 50603 Kuala Lumpur, Malaysia. Tel: \\ 603-7967-7355. E-mail: aleebrahim@um.edu.my
}

Received: February 8, 2014 Accepted: March 12, 2014 Online Published: March 30, 2014

doi:10.5539/ies.v7n4p120 URL: http://dx.doi.org/10.5539/ies.v7n4p120

\begin{abstract}
The number of publications is the first criteria for assessing a researcher output. However, the main measurement for author productivity is the number of citations, and citations are typically related to the paper's visibility. In this paper, the relationship between article visibility and the number of citations is investigated. A case study of two researchers who are using publication marketing tools confirmed that the article visibility will greatly improve the citation impact. Some strategies to make the publications available to a larger audience have been presented at the end of this paper.
\end{abstract}

Keywords: H-index, research tools, increase citations, publication marketing, bibliometrics, improve citations, maximized research visibility, increase research impact

\section{Introduction}

Citation shows that how many times an article has been used by other articles. Citations are applied to measure the importance of information contained in an article (Fooladi et al., 2013). "The more often a paper become cited the greater its influence on the field" is a basic assumption of citation analysis (Martínez et al., 2013; Garfield \& Merton, 1979). Direct citation remains a main indicator of the significance of a research output rather than alternative metrics (Shotton, 2013; Priem, 2013). In addition, the number of citations has over $20 \%$ share in different university ranking systems (Usher \& Savino, 2007; Taylor \& Braddock, 2007). Therefore, most of the universities encourage their researchers to publish high quality papers which can receive high citations and will reach the widest possible audience (Ale-Ebrahim et al., 2013). Consequently, the number of citations will be limited to the availability of the published article on the web (Lawrence, 2001). The literature has shown increased visibility by making research outputs available through open access repositories, results wider access and higher citation impact (Antelman, 2004; Hardy et al., 2005; Amancio et al., 2012; Ertürk \& Şengül, 2012; Dalton, 2013). A paper has greater chance of becoming highly cited whenever has more visibility (Egghe et al., 2013). Antelman (2004) approved across mathematics, electrical and electronic engineering, political science, and philosophy disciplines, freely available articles have a greater research impact than articles which are not open-access to the users. As a result, most authors are motivated to publish in an open-access journal for increasing visibility and subsequently a citation advantage (Jayaprakash et al., 2013). Publishing in an open-access journal has been generally associated with a 10\% boost in citations (McCabe \& Snyder, 2013).

Moreover, Lawrence (2001) investigated the impact of free online availability of article. However, the citation will be increased due to the quality and visibility of the paper (Kurtz et al., 2005). Visibility can ultimately be translated to increased opportunity for attracting citations (Mirjana et al., 2013). A plenty of time and effort has 
been spent by researchers during writing up their research for publication. However, publishing a paper in the journal which has a high impact factor is not guaranteed by analyzing citation rate. The results were dramatic. There is a clear correlation between the number of times an article is cited and the probability that the article is online (Lawrence, 2001). Author self-archiving is promising to increase visibility of the articles and clearly perceived benefits in sharing scholarly output. Self-archiving is defined as storing the scientific research outputs in researchers' own web pages/sites, organizational web sites or institutional repositories (Ertürk \& Şengül, 2012). The advantages of self-archiving an article are:

- The article can be accessible to wider audiences by a simple Google search,

- The article will be ensured archival access, and

- The author can add additional information related to the published article.

The World Wide Web has become an outstanding tool for the collection and dissemination of scholarly Information (Más-Bleda \& Aguillo, 2013). The majority of freely available articles will be found on author personal website rather than in a repository or in an open-access journal (Antelman, 2004). Alternatively, institutional repositories make articles visible and increase the chances for use by other scholars and exchange ideas among similar disciplines (Ngah, 2010). Eysenbach (2006) stated that more visibility resulted in:

- More citations.

- Article cited sooner.

- Citations continue at a significant rate for a longer period of time.

Lack of visibility caused that some senior scholars in some African universities may not have a significant citation impact (Rotich \& Musakali, 2013). Writing an article for online distribution needs to cover some techniques from writing a search engine-friendly title and abstract to maximize visibility once it is published (Norman, 2012). Depositing the paper in the institutional repository is another way of increasing paper's visibility. Commonly cited benefits of using an institutional repository are to increase the visibility and citation impact of the institution's scholarship (Tate, 2010). By making a few adjustments in how and where to publish and present the research findings, researchers can become more productive, better known for their research, and better connected with the members of your professional community (Pfirman et al., 2007).

There are tools that help in enhancing the visibility and readership of research papers. Effective use of these tools can result in increased visibility and, thus, improve the paper citations (Ale-Ebrahim, 2013). In this study, we implemented the tools for increasing the visibility of two researchers' papers from two different disciplines and universities. The way of approaching to increase the visibility and the obtained results will be discussed in the following sections of this paper.

\section{Method}

An article needs to show up in search results, then received download count and citations. Consider one scientist has published some articles with a certain amount of visibility. We define each version of one article which is available through the internet as a new visibility. Therefore, increasing the visibility menus increases the number of versions of an article when we are looking for through Google Scholar (http://scholar.google.com). Visibility is in turn determined by how avidly published work is received by the academic or scientific community (Miguel et al., 2011). The universities also be ranked based on Web visibility by the Cybermetrics Lab at CSIC (Aguillo et al., 2010). Therefore, web visibility of an article is essential. This research tries to determine the paper visibility effect on the citations of two different researchers (researcher "A" with a social science background and researcher "B" with computer science education) from different disciplines and universities. As a first approximation, the visibility contribution to citation could be estimated as equal in both conditions. The Google Scholar citation is used as an indicator for measuring the effect of visibility on the citation. The trend of the citation before and after increasing the visibility makes a good indicator for demonstrating the advertisements role. The Google Scholar citation was used to collect the data. The techniques listed in Table 1 were implemented from December 2011 to January 2012. 
Table 1. Techniques used to make the publications available to a larger audience

\begin{tabular}{ll}
\hline Tip & Source \\
\hline Publish in an open-access journal & $\begin{array}{l}\text { (Jayaprakash et al., 2013; Mirjana et al., 2013; } \\
\text { Koulouris et al., 2013; Bernal, 2013) }\end{array}$ \\
\hline Writing a search engine-friendly title and abstract & (Norman, 2012; Beel et al., 2010). \\
\hline Availability of the articles on author personal website & (Antelman, 2004; Más-Bleda \& Aguillo, 2013) \\
\hline Deposit the paper in the institutional repository & (Tate, 2010; Ngah, 2010; Koulouris et al., 2013) \\
\hline
\end{tabular}

\section{Results and Discussions}

Figure 1 to 4 show the Google Scholar citation trend of the two anonymous researchers that are using publication marketing tools since the beginning of 2012. The results indicate the effectiveness of publication marketing tools in increasing the visibility and subsequently increasing the paper citations. The researcher "A" received maximum four citations per year before implementing the publication marketing tools. A year after the research A received around 20 citations (Figure 1) and it remained at the same growth level for sequence year. Therefore, two years after increasing the visibility of the published papers the total number of citations reached at 34 (Figure 2). The same trends can be seen in the other researchers in the social science from our databases. However, in this study only two researchers isolate from other factors which could be affected in their published paper citations. As a result, the use of publication marketing techniques increases citations from four in 2011 to 34 in 2013. Although, the sample of two controlled anonymous authors might be considered is too small. Nevertheless, the literature and evidence from other researcher in this study prove the causal relationship between the paper visibility and citations.

\begin{tabular}{|l|c|c|}
\hline \multicolumn{3}{|c|}{ Citation indices } \\
\hline & All & Since 2008 \\
\hline Citations & 63 & 52 \\
\hline h-index & 4 & 4 \\
\hline i10-index & 1 & 0 \\
\hline
\end{tabular}

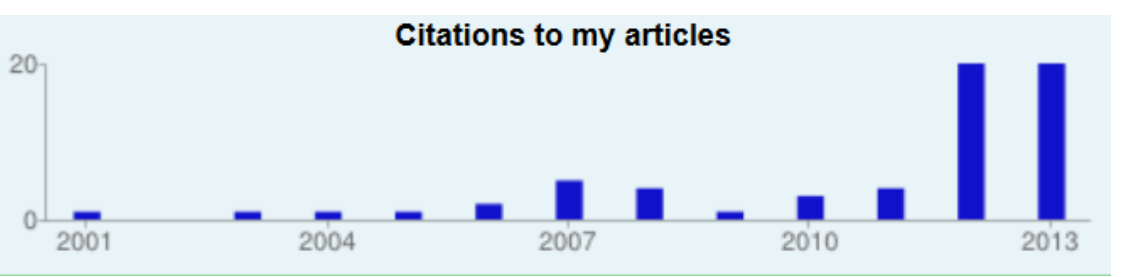

Figure 1. The Google Scholar citation trend for researcher "A”, the data retrieved on 25 September 2013

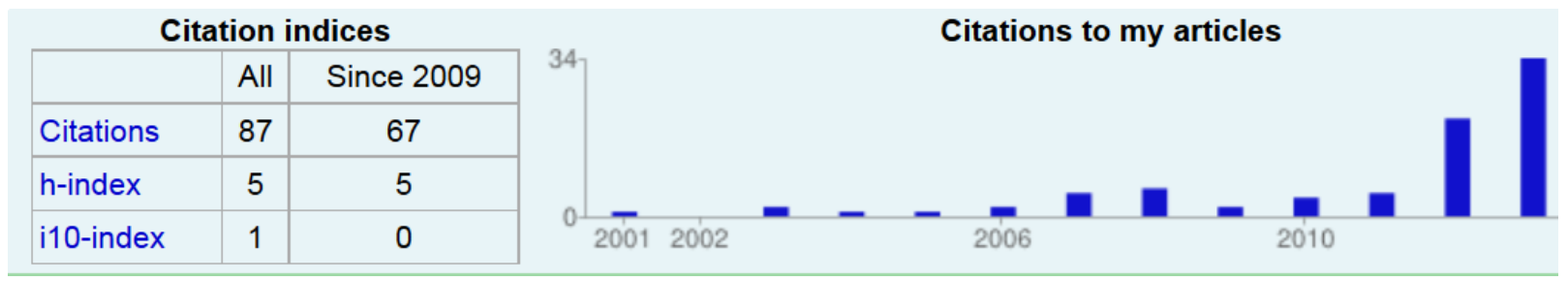

Figure 2. The Google Scholar citation trend for researcher "A", the data retrieved on 25 February 2013

The researcher "B" received maximum 17 citations per year before implementing the publication marketing tools. A year after the research B received around 200 (Figure 3) citations and it remained at the same level for sequence year (Figure 4). The Researcher "B" received over 140 citations in less than five months from 07 October 2013 to 25 February 2013. The comparison between the current trends of citations and their total citations in the year of 2011 for the researcher "B" is inaugurating a dramatic increase. Based on Hirsch (2005), "A scientist has index $\mathrm{h}$ if $\mathrm{h}$ of his/her Np papers has at least $\mathrm{h}$ citations each, and the other $(\mathrm{Np}-\mathrm{h})$ papers have $\leq$ $\mathrm{h}$ citations each". The H-index has been considered as an objective tool that can assess research performance through citation analysis (Patel et al., 2013). The H-index, proposes a simple and apparently strong measure to compare the scientific productivity and visibility (Farhadi et al., 2013). The h-index has received a lot of attention from the scientific community since 2005 due to some of their easiness of computation, balance between quantity of publications and their impact (Alonso et al., 2009). A major characteristic of the h-index is 
the combination of productivity and impact of research which offering the possibility of measuring the lifetime achievement of scholars, based on their scientific output (Arencibia-Jorge \& Rousseau, 2009). Hirsch suggests that after 20 years in research, an h of 20 is a sign of success, and one of 40 indicates outstanding scientists likely to be found only in the major research laboratories (Ball, 2005). Therefore, the growth of $h$ which we achieved in this research, can be categorized the researcher's as an outstanding scientist. Because of the initial H-index for research A was $h=3$ with total citations of 26. The research B, H-index growth from $h=3$ to $h=13$ within two years. The visibility, increased the citation and chronologically H-index of both researchers. The paper will receive a citation if a researcher finds the content of the paper is relevant and they know it exists. This study by increasing the probability of finding a paper through search engines increased the author's citations.

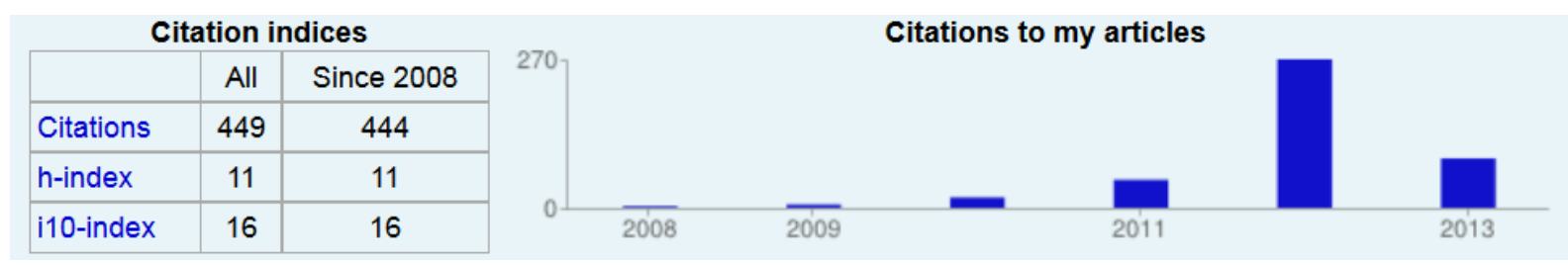

Figure 3. The Google Scholar citation trend for researcher "B", the data retrieved on 07 October 2013

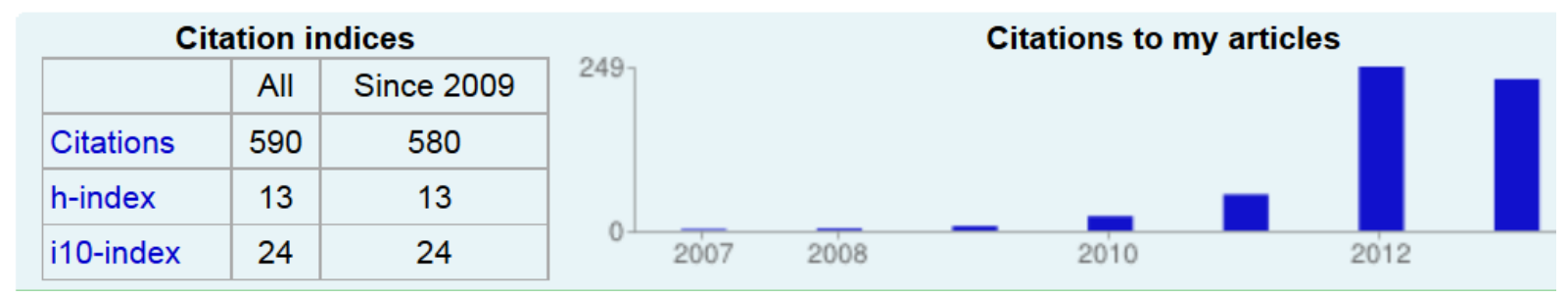

Figure 4. The Google Scholar citation trend for researcher "B", the data retrieved on 25 February 2013

\section{Conclusion}

This empirical study has shown that although a paper may not be written and published in a high quality manner and journal, it is still possible for the paper to acquire adequate citations and world-wide recognition. Once a paper visibility increases, the citation will be increased at a significant rate. Therefore, a few simple techniques can enhance article's visibility. The results of the study indicate that self- archiving of the articles will greatly improve the visibility and citation impact of the articles. To make sure a research output is as accessible as possible, published papers can be disseminated through free repositories. Significant improvement in the times paper cited can be seen by comparing the number of citations before and after using publication marketing tools.

\section{Acknowledgements}

The authors would like to thank Mr. Mahdi Sharifi and Mr. Morteza Yousefi for providing practical support. We also acknowledge the reviewers and the journal editor for their insightful suggestions.

\section{References}

Aguillo, I. F., Bar-Ilan, J., Levene, M., \& Ortega, J. L. (2010). Comparing university rankings. Scientometrics, 85, 243-256. http://dx.doi.org/10.1007/s11192-010-0190-z

Ale-Ebrahim, N. (2013). Introduction to the Research Tools Mind Map. Research World, 10, 1-3. http://dx.doi.org/10.5281/zenodo.7712

Ale-Ebrahim, N., Salehi, H., Embi, M. A., Habibi-Tanha, F., Gholizadeh, H., Motahar, S. M., \& Ordi, A. (2013). Effective Strategies for Increasing Citation Frequency. International Education Studies, 6, 93-99. http://dx.doi.org/10.5539/ies.v6n11p93

Alonso, S., Cabrerizo, F. J., Herrera-Viedma, E., \& Herrera, F. (2009). h-Index: A review focused in its variants, computation and standardization for different scientific fields. Journal of Informetrics, 3, 273-289. http://dx.doi.org/10.1016/j.joi.2009.04.001

Amancio, D. R., Oliveira Jr, O. N., \& Da Fontoura, C. L. (2012). Three-feature model to reproduce the topology 
of citation networks and the effects from authors' visibility on their h-index. Journal of Informetrics, 6, 427-434. http://dx.doi.org/10.1016/j.joi.2012.02.005

Antelman, K. (2004). Do open-access articles have a greater research impact? College \& research libraries, 65, 372-382.

Arencibia-Jorge, R., \& Rousseau, R. (2009). Influence of individual researchers' visibility on institutional impact: An example of Prathap's approach to successive h-indices. Scientometrics, 79, 507-516. http://dx.doi.org/10.1007/s11192-007-2025-0

Ball, P. (2005). Index aims for fair ranking of scientists. Nature, 436, 900. http://dx.doi.org/10.1038/436900a

Beel, J., Gipp, B., \& Wilde, E. (2010). Academic Search Engine Optimization (ASEO). Journal of Scholarly Publishing, 41, 176-190.

Bernal, I. (2013). Open Access and the Changing Landscape of Research Impact Indicators: New Roles for Repositories. Publications, 1, 56-77. http://dx.doi.org/10.3390/publications 1020056

Dalton, M. (2013). A dissemination divide? The factors that influence the journal selection decision of Library \& Information Studies (LIS) researchers and practitioners. Library and Information Research, 37, 33-57.

Egghe, L., Guns, R., \& Rousseau, R. (2013). Measuring co-authors' contribution to an article's visibility. Scientometrics, 95, 55-67. http://dx.doi.org/10.1007/s11192-012-0832-4

Ertürk, K., \& Şengül, G. (2012). Self Archiving in Atılım University. In S. Kurbanoğlu, U. Al, P. Erdoğan, Y. Tonta, \& N. Uçak (Eds.), E-Science and Information Management. Berlin, Heidelberg: Springer.

Eysenbach, G. (2006). Citation Advantage of Open Access Articles. PLoS Biol, 4, e157. http://dx.doi.org/10.1371/journal.pbio.0040157

Farhadi, M., Salehi, H., Embi, M. A., Fooladi, M., Farhadi, H., Aghaei-Chadegani, A., \& Ale-Ebrahim, N. (2013). Contribution of Information and Communication Technology (ICT) in Country'S H-Index. Journal of Theoretical and Applied Information Technology, 57, 122-127. http://dx.doi.org/10.5281/zenodo.7715

Fooladi, M., Salehi, H., Yunus, M. M., Farhadi, M., Aghaei-Chadegani, A., Farhadi, H., \& Ale-Ebrahim, N. (2013). Do Criticisms Overcome the Praises of Journal Impact Factor? Asian Social Science, 9, 176-182. http://dx.doi.org/10.5539/ass.v9n5p176

Garfield, E., \& Merton, R. K. (1979). Citation indexing: Its theory and application in science, technology, and humanities. Wiley New York.

Hardy, R., Oppenheim, C., Brody, T., \& Hitchcock, S. (2005). Open Access Citation Information.

Hirsch, J. E. (2005). An index to quantify an individual's scientific research output. Proceedings Of The National Academy of Sciences Of The United States Of America, 102, 16569-16572. http://dx.doi.org/10.1073/pnas.0507655102

Jayaprakash, K., Rekha, A., \& Rajendiran, S. (2013). Open Access Journals-A Study. IOSR Journal Of Humanities And Social Science, 8, 07-09.

Koulouris, A., Kyriaki-Manessi, D., Giannakopoulos, G., \& Zervos, S. (2013). Institutional Repository Policies: Best Practices for Encouraging Self-Archiving. Procedia-Social and Behavioral Sciences, 73, 769-776.

Kurtz, M. J., Eichhorn, G., Accomazzi, A., Grant, C., Demleitner, M., Henneken, E., \& Murray, S. S. (2005). The effect of use and access on citations. Information Processing \& Management, 41, 1395-1402. http://dx.doi.org/10.1016/j.ipm.2005.03.010

Lawrence, S. (2001). Free online availability substantially increases a paper's impact. Nature, $411,521$. http://dx.doi.org/10.1038/35079151

Martínez, M. A., Herrera, M., López-Gijón, J., \& Herrera-Viedma, E. (2013). H-Classics: Characterizing the concept of citation classics through H-index. Scientometrics, 1-13.

Más-Bleda, A., \& Aguillo, I. (2013). Can a personal website be useful as an information source to assess individual scientists? The case of European highly cited researchers. Scientometrics, 1-17.

Mccabe, M. J., \& Snyder, C. M. (2013). Does Online Availability Increase Citations? Theory and Evidence from a Panel of Economics and Business Journals. SSRN working paper.

Miguel, S., Chinchilla-Rodriguez, Z., \& De Moya-Anegon, F. (2011). Open Access and Scopus: A New Approach to Scientific Visibility From the Standpoint of Access. Journal of the American Society for 
Information Science and Technology, 62, 1130-1145. http://dx.doi.org/10.1002/asi.21532

Mirjana, I., Miloš, R., Vladimir, K., \& Jovana, V. (2013). Computer Science and Information Systems: Publishing an international Open Access journal in a developing country. Journal Publishing in Developing Transition and Emerging Countries: Proceedings of the 5th Belgrade International Open Access Conference 2012; Fifth Belgrade International Open Access Conference 2012.

Ngah, Z. A. (2010). Open Access repositories and journals for visibility: Implications for Malaysian libraries. Malaysian Journal of Library \& Information Science, 15.

Norman, E. R. (2012). Maximizing Journal Article Citation Online: Readers, Robots, and Research Visibility. Politics \& Policy, 40, 1-12. http://dx.doi.org/10.1111/j.1747-1346.2011.00342.x

Patel, V. M., Ashrafian, H., Bornmann, L., Mutz, R., Makanjuola, J., Skapinakis, P., . . Athanasiou, T. (2013). Enhancing the $\mathrm{h}$ index for the objective assessment of healthcare researcher performance and impact. Journal of the Royal Society of Medicine, 106, 19-29. http://dx.doi.org/10.1258/jrsm.2012.120253

Pfirman, S., Balsam, P., Bell, R., Laird, J., \& Culligan, P. (2007). Maximizing Productivity and Recognition, Part 1: Publication, Citation, and Impact.

Priem, J. (2013). Scholarship: Beyond the paper. Nature, 495, 437-440. http://dx.doi.org/10.1038/495437a

Rotich, D. C., \& Musakali, J. J. (2013). Publish or Perish: Remaining Academically Relevant and Visible In the Global Academic Scene through Scholarly Publishing. In Ocholla, N. E. D. N. (Ed.), Conference and Programme Chairs, 2013 South Africa. Department of Information Studies-University of Zululand, 58.

Shotton, D. (2013). Publishing: Open citations. Nature, 502, 295-297. http://dx.doi.org/10.1038/502295a

Tate, J. (2010). An evaluation of SOAS Research Online, the Institutional Repository of the School of Oriental and African Studies-SOAS Research Online. CITY UNIVERSITY.

Taylor, P., \& Braddock, R. (2007). International University Ranking Systems and the Idea of University Excellence. Journal of Higher Education Policy and Management, 29, 245-260. http://dx.doi.org/10.1080/13600800701457855

Usher, A., \& Savino, M. (2007). A Global Survey of University Ranking and League Tables. Higher Education in Europe, 32, 5-15. http://dx.doi.org/10.1080/03797720701618831

\section{Copyrights}

Copyright for this article is retained by the author(s), with first publication rights granted to the journal.

This is an open-access article distributed under the terms and conditions of the Creative Commons Attribution license (http://creativecommons.org/licenses/by/3.0/). 